\title{
PELAKSANAAN SUPERVISI PENDIDIKAN OLEH KEPALA SEKOLAH DALAM MENINGKATKAN PROFESIONAL GURU BIMBINGAN KONSELING DI SMP NEGERI 8 PALOPO
}

\author{
1Sumardin Raupu, ${ }^{2}$ Dwi Risky Arifanti \\ ${ }^{1}$ Institut Agama Islam Negeri Palopo \\ 2Institut Agama Islam Negeri Palopo \\ E-mail: sumardin aldhy@iainpalopo.ac.id
}

\begin{abstract}
Educational supervision is an effort to guide school principals to teachers, and guidance counseling teachers in schools in order to improve the quality of teaching and learning in schools. The purpose of this study is to find out 1) The process of preparing the principal's supervision program in increasing the professional competence of the counseling guidance teacher, 2) The implementation of the educational supervision program by the principal in improving the professional competence of the counseling guidance teacher, and 3) The principal's follow-up in implementing the supervision of education for improve the professional competence of counseling guidance teachers. This research uses descriptive method with a qualitative approach. Data collection techniques are observation, interview and documentation. Research subjects were the principal, vice principal and counseling guidance teacher. The results of his research show that: 1) The supervision program of the headmaster of Palopo 8 Junior High School was prepared at the beginning of each semester of the school year by involving the deputy headmaster, counseling guidance teacher, and teacher in the field of study. The supervision program includes the activities of professional teacher guidance and guidance as well as training for teachers that are tailored to their fields. 2) The supervision of the head of SMP Negeri 8 Palopo follows the program that has been prepared, the technique used is through teacher meetings, classroom observations and personal conversations. Especially for classroom observation techniques, they have already used observation guidelines, but the quantity in the implementation has not been maximized. 3) The follow-up supervision of the headmaster of Palopo 8 Junior High School was observed through individual talks, giving advice, coaching, and guiding counseling guidance teachers with a focus on better implementation of activities, but the principal did not fully understand the counseling guidance program
\end{abstract}

\section{Keywords: Educational Supervision, Principal and Counseling Guidance}

\begin{abstract}
Abstrak
Supervisi pendidikan merupakan upaya pembinaan kepala sekolah kepada guru, dan guru bimbingan konseling di sekolah dalam rangka meningkatkan kualitas proses belajar mengajar di sekolah. Tujuan penelitian ini untuk mengetahui 1) Proses penyusunan program supervisi kepala sekolah dalam meningkatkan kompetensi profesional guru bimbingan konseling, 2) Pelaksanaan program supervisi pendidikan oleh kepala sekolah dalam meningkatkan kompetensi profesional guru bimbingan konseling, dan 3) Tindak lanjut kepala sekolah dalam pelaksanaan supervisi pendidikan untuk meningkatkan kompetensi profesional guru bimbingan konseling. Penelitian ini menggunakan metode deskriptif dengan pendekatan kualitatif. Teknik pengumpulan data adalah observasi, wawancara dan dokumentasi. Subjek penelitian adalah kepala sekolah, wakil kepala sekolah dan guru bimbingan konseling. Hasil penelitiannya menunjukan bahwa: 1) Program supervisi kepala SMP Negeri 8 Palopo disusun di awal semester setiap tahun ajaran dengan mengikutsertakan wakil kepala sekolah, guru bimbingan konseling, serta guru bidang studi. Program supervisi mencakup kegiatan pembinaan dan bimbingan profesional guru serta
\end{abstract}




\section{2 | Sumardin Raupu, Dwi Risky Arifanti}

pelatihan bagi guru yang disesuaikan dengan bidangnya. 2) Pelaksanaan supervisi kepala SMP Negeri 8 Palopo mengikuti program yang telah disusun, teknik yang digunakan adalah melalui rapat guru, observasi kelas dan percakapan pribadi. Khusus untuk teknik observasi kelas sudah menggunakan panduan observasi, namun kuantitas pada pelaksanaannya belum maksimal. 3) Tindak lanjut pelaksanaan supervisi kepala SMP Negeri 8 Palopo diobservasikan melalui pembicaraan individual, pemberian saran, pembinaan, serta membimbing guru bimbingan konseling dengan fokus untuk pelaksanaan kegiatan yang lebih baik, namun kepala sekolah tidak sepenuhnya memahami program bimbingan konseling

Kata Kunci: Supervisi Pendidikan, Kepala Sekolah dan Bimbingan Konseling

\section{PENDAHULUAN}

Pendidikan merupakan suatu aktivitas yang dilakukan oleh manusia dalam kehidupan seharihari baik secara formal, non formal, maupun informal yang bertujuan untuk memperbaiki, dan meningkatkan kualitas kehidupan manusia. Peningkatan mutu pendidikan berkaitan erat dengan sumber daya manusia. Peningkatan mutu pendidikan merupakan tujuan pembangunan di bidang pendidikan nasional serta merupakan bagian integral dari upaya peningkatan kualitas manusia Indonesia secara menyeluruh. Tujuan pendidikan yang tertera dalam Undang-Undang Republik Indonesia Nomor 20 Tahun 2003 Bab II Pasal 3 tentang sistem pendidikan Nasional (Sisdiknas) sebagai berikut: Mengembangkan kemampuan dan membentuk watak serta peradaban bangsa yang bermartabat dalam rangka mencerdaskan kehidupan bangsa, bertujuan untuk berkembangnya potensi peserta didik agar menjadi manusia yang beriman dan bertakwa kepada Tuhan yang maha Esa, beraklak mulia, sehat, berilmu, cakap, kreatif, mandiri dan menjadi warga negara yang demokratis serta bertanggung jawab. ${ }^{1}$

Bimbingan konseling merupakan program yang dilaksanakan oleh guru bimbingan dan konseling berada di bawah sub-organisasi sekolah yang di koordinasi oleh kepala sekolah dengan tujuan untuk memberi manfaat bagi siswa Pogram bimbingan dan konseling di sekolah tidak akan berhasil dan berjalan secara efektif dan efesien apabila tidak ada dukungan dan perhatian dari kepala sekolah. Perhatian dan dukungan kepala sekolah terhadap petugas bimbingan dan konseling (konselor) sangat diperlukan untuk meningkatkan program bimbingan dan konseling yaitu memberikan informasi tentang bimbingan dan konseling kepada siswa, mengadakan rapat khusus, menyediakan fasilitas dan menghargai keberadaan program bimbingan dan konseling bertujuan agar program bimbingan konseling dapat berjalan efektif.

\footnotetext{
${ }^{1}$ Depdiknas, Undang-undang RI Nomor 20 Tahun 2003 tentang Sistem Pendidikan
} Nasional, t.t. 
Berkaitan dengan masalah di atas, maka penulis tertarik untuk mengadakan penelitian yang berjudul: " Pelaksanaan Supervisi Pendidikan Oleh Kepala Sekolah Dalam Meningkatkan Profesional Guru Bimbingan Konseling di SMP Negeri 8 Palopo" Adapun pertanyaan penelitian yang diajukan adalah: Bagaimanakah proses penyusunan program supervisi pendidikan oleh kepala sekolah dalam meningkatkan profesional guru bimbingan dan konseling di SMP Negeri 8 Palopo? Bagaimanakah pelaksanaan program supervisi pendidikan oleh kepala sekolah dalam meningkatkan profesional guru bimbingan dan konseling di SMP Negeri 8 Palopo?

\section{METODE}

Metode yang digunakan dalam penelitian ini adalah metode deskriptif dengan pendekatan kualitatif. Satori dan Komariah mendefinisikan penelitian kualitatif adalah" suatu penelitian yang mengungkapkan situasi sosial tertentu dengan mendeskripsikan kenyataan secara benar, dibentuk oleh kata-kata berdasarkan teknik pengumpulan dan analisis data yang releven yang diperoleh dari situasi yang alamiah". ${ }^{2}$ Penelitian ini dilakukan pada SMP Negeri 8 Palopo. Adapun subjek dalam penelitian ini adalah kepala sekolah, wakil kepala sekolah dan guru bimbingan konseling. Teknik pengumpulan data dilakukan dengan cara observasi, wawancara, dan dokumentasi.

\section{PROSES PENYUSUNAN PROGRAM SUPERVISI PENDIDIKAN OLEH KEPALA SEKOLAH DALAM MENINGKATKAN KOMPETENSI PROFESIONAL GURU BIMBINGAN DAN KONSELING DI SMP NEGERI 8 PALOPO.}

Program supervisi kepala SMP Negeri 8 Palopo disusun di awal semester setiap tahun ajaran dengan mengikutsertakan wakil kepala sekolah, guru bimbingan konseling, serta guru bidang studi. Program supervisi mencakup kegiatan pembinaan dan bimbingan profesional guru serta pelatihan bagi guru yang disesuaikan dengan bidangnya.

Kepala sekolah sebagai supervisor pada saat melakukan supervisi terhadap stafnya seyogiyanya melaksanakan tugas dan tanggung jawabnya dengan baik. Fungsi utama sebagai supervisor kepala sekolah juga berfungsi dan berperan sebagai administrator. Mulyasa menyatakan bahwa" kepala sekolah sebagai administrator memiliki hubungan yang sangat erat dengan

\footnotetext{
${ }^{2}$ Satori D dan Komariah A, Metodologi Penelitian Kualitatif (Bandung: Alfabeta, 2013), h.25.
} 
berbagai aktivitas pengelolaan administrasi yang bersifat pencatatan, penyusunan dan pendokumen seluruh program sekolah". ${ }^{3}$

\section{PELAKSANAAN PROGRAM SUPERVISI PENDIDIKAN OLEH KEPALA SEKOLAH DALAM MENINGKATKAN KOMPETENSI PROFESIONAL GURU BIMBINGAN DAN KONSELING DI SMP NEGERI 8 PALOPO.}

Pelaksanaan supervisi pendidikan berdasarkan jadwal yang telah ditentukan yaitu di awal semester setiap tahun ajaran melalui melalui teknik rapat guru, observasi kelas dan percakapan pribadi. Khusus untuk teknik observasi kelas sudah menggunakan panduan observasi, namun kuantitas pada pelaksanaannya belum maksimal. Hal ini dapat dilihat dari jumlah pelaksanaan supervisi pada setiap guru tidak sama .

Supervisi yang dilakukan kepala sekolah merupakan pembinaan kepala sekolah terhadap keprofesionalan guru yaitu sebagai susunan supervisi akademik dengan tujuan memperdayakannya terhadap pelaksanaan tanggung jawabnya sebagai tenaga profesional dalam memanifestasikan kinerja pembelajaran terhadap peserta didik. Wahjosumidjo menyatakan bahwa" kepala sekolah bertanggung jawab dan mempertanggungjawabkan atas segala tindakan yang dilakukan oleh bawahannya". ${ }^{4}$

\section{TINDAK LANJUT KEPALA SEKOLAH DALAM PELAKSANAAN SUPERVISI PENDIDIKAN DALAM MENINGKATKAN KOMPETENSI PROFESIONAL GURU BIMBINGAN KONSELING DI SMP NEGERI 8 PALOPO.}

Tindak lanjut pelaksanaan supervisi kepala sekolah diobservasikan melalui pembicaraan individual, pemberian saran, pembinaan serta membimbing guru bimbingan konseling dengan fokus untuk pelaksanaan kegiatan yang lebih baik. Hal ini dapat dilihat dari upaya kepala SMP Negeri 8 Palopo dengan mengirim guru bimbingan konseling ke penataran program bimbingan konseling, namun kepala sekolah tidak sepenuhnya memahami program bimbingan konseling.

Tindak lanjut supervisi pendidikan merupakan upaya kepala sekolah dalam memberikan layanan profesional melalui pembinaan kepada guru

\footnotetext{
${ }^{3}$ Mulyasa E, Menjadi Kepala Sekolah Profesional (Bandung: Remaja Rosda Karya, 2007), h.107.

${ }^{4}$ Wahjosumidjo, Kepemimpinan Kepala Sekolah Tinjau Teoritik dan Permasalahannya, h.97.
} 
dengan tujuan untuk meningkatkan kualitas profesional guru sehingga kualitas pertumbuhan peserta didik dapat tercapai dengan baik. Engkoswara dan Komariah menyatakan bahwa "supervisi pendidikan merupakan suatu proses memberikan layanan profesional pendidikan melalui pembinaan yang kontinu kepada guru dan personil sekolah lainnya untuk memperbaiki dan meningkatkan efektivitas kinerja personalia sehingga dapat mencapai pertumbuhan peserta didik". ${ }^{5}$

\section{PENUTUP}

Berdasarkan hasil analisis data maka dapat disimpulkan bahwa Program supervisi kepala SMP Negeri 8 Palopo disusun di awal semester setiap tahun ajaran dengan melibatkan wakil kepala sekolah, guru bimbingan konseling, serta guru bidang studi. Program supervisi mencakup kegiatan pembinaan dan bimbingan profesional guru serta pelatihan bagi guru yang berkaitan dengan bidangnya. Penyusunan program supervisi pendidikan yang baik berimplikasikan pada peningkatan sumber daya guru bimbingan konseling bisa dilakukan dengan bantuan supervisor atau instansi yang melakukan kegiatan supervisi pada guru bimbingan konseling. Pelaksanaan program supervisi kepala SMP Negeri 8 Palopo mengikuti program yang telah disusun melalui teknik rapat guru, observasi kelas dan percakapan pribadi. Untuk teknik observasi kelas sudah menggunakan panduan oservasi, namun kuantitas pada pelaksanaannya belum maksimal. Hal ini dapat dilihat dari jumlah pelaksanaan supervisi pada setiap guru tidak sama. Tindak lanjut pelaksanaan supervisi kepala SMP Negeri 8 Palopo diobservasikan melalui pembicaraan individual, pemberian saran, pembinaan serta bimbingan kepada guru bimbingan konseling dengan fokus untuk pelaksanaan kegiatan yang lebih baik. Sehingga kepala sekolah meupayakan pengiriman guru bimbingan konseling ke penataran yang berhubungan dengan program bimbingan konseling, namun kepala sekolah tidak sepenuhnya memahami program bimbingan konseling

Disarankan agar Program supervisi pendidikan yang disusun kepala sekolah bersama personel sekolah yang terlibat membantunya dapat dijadikan pedoman dalam aspek perencanaan kegiatan supervisi lebih ditingkatkan lagi. Pelaksanaan program supervisi yang mengikuti program yang telah ada dijadikan sebagai pedoman kepala sekolah, agar kuantitas pelaksanaan supervisi menjadi lebih baik. Tindak lanjut dalam pelaksanaan program supervisi pendidikan diobservasikan melalui pembicaraan individual, pemberian saran, pembinaan serta bimbingan kepada guru

\footnotetext{
${ }^{5}$ Engkoswara dan Komariah, Administrasi Pendidikan (Bandung: Alfabeta, 2015), h.229.
} 
bimbingan konseling sebagai upaya kepala sekolah dalam memperbaiki program supervisi yang sedang berlangsung.

Keterbatasan penelitian ini adalah masih banyak hal yang perlu di perhatikan dalam pelaksanaan supervisi pendidikan. Untuk itu disarankan kepada peneliti yang akan melakukan penelitian serupa, hendaknya menambahkan faktor apa saja yang menyebabkan tinggi rendahnya kompetensi guru sehingga dapat pada saat melakukan supervisi hasilnya lebih baik lagi.

\section{DAFTAR PUSTAKA}

Danim, dan Khairil. Profesi Kependidikan. Bandung: Alfabeta, 2011.

Depdiknas. Undang-undang RI Nomor 20 Tahun 2003 tentang Sistem Pendidikan Nasional, t.t.

Engkoswara, dan Komariah. Administrasi Pendidikan. Bandung: Alfabeta, 2015.

Fathurrohman, P, dan Suryana A. Supervisi Pendidikan. Bandung: Revika Aditama, 2011.

Hikmawati. Bimbingan Konseling. Jakarta: Raja Grafindo Persada, 2011.

Makawimbang. Supervisi dan Peningkatan Mutu Pendidikan. Bandung: Alfabeta, 2011.

Mulyasa E. Menjadi Kepala Sekolah Profesional. Bandung: Remaja Rosda Karya, 2007.

Purwanto N.M. Administrasi dan Supervisi Pendidikan. Bandung: Rosda Karya, 2009.

Satori D, dan Komariah A. Metodologi Penelitian Kualitatif. Bandung: Alfabeta, 2013.

Wahjosumidjo. Kepemimpinan Kepala Sekolah Tinjau Teoritik dan Permasalahannya. Jakarta: PT Raja Grafindo Persada, 2009.

Yusuf, dan Nurihsan J. Landasan Bimbingan dan Konseling. Bandung: Rosda Karya, 2011. 